
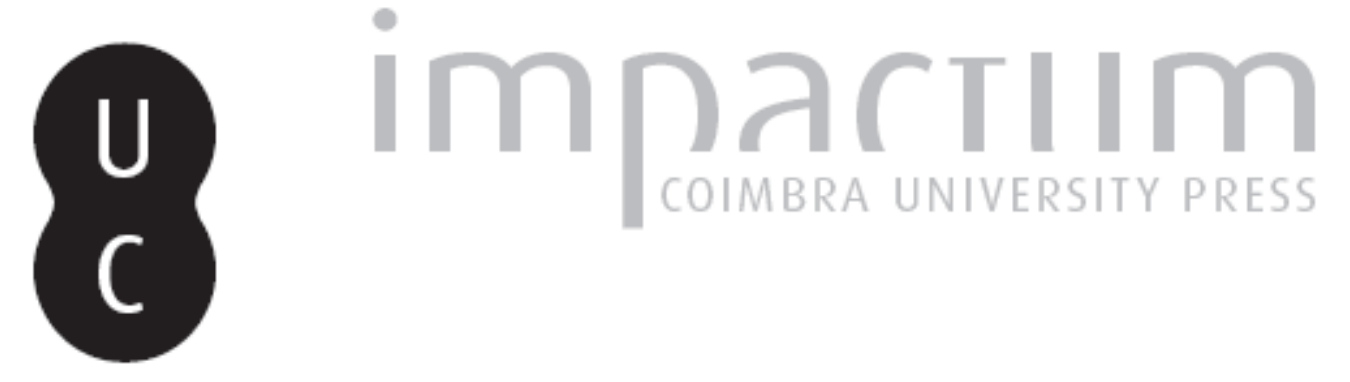

Museus e desenvolvimento local: o exemplo do Museu do Pão (Seia)

Autor(es): $\quad$ Amado, Marta; Carvalho, Paulo

Publicado por: $\begin{aligned} & \text { Faculdade de Letras da Universidade de Coimbra, Departamento de } \\ & \text { Geografia }\end{aligned}$

URL

persistente:

URI:http://hdl.handle.net/10316.2/30228

DOI:

DOI:http://dx.doi.org/10.14195/0871-1623_32_20

Accessed : $\quad$ 26-Apr-2023 15:12:09

A navegação consulta e descarregamento dos títulos inseridos nas Bibliotecas Digitais UC Digitalis, UC Pombalina e UC Impactum, pressupõem a aceitação plena e sem reservas dos Termos e Condições de Uso destas Bibliotecas Digitais, disponíveis em https://digitalis.uc.pt/pt-pt/termos.

Conforme exposto nos referidos Termos e Condições de Uso, o descarregamento de títulos de acesso restrito requer uma licença válida de autorização devendo o utilizador aceder ao(s) documento(s) a partir de um endereço de IP da instituição detentora da supramencionada licença.

Ao utilizador é apenas permitido o descarregamento para uso pessoal, pelo que o emprego do(s) título(s) descarregado(s) para outro fim, designadamente comercial, carece de autorização do respetivo autor ou editor da obra.

Na medida em que todas as obras da UC Digitalis se encontram protegidas pelo Código do Direito de Autor e Direitos Conexos e demais legislação aplicável, toda a cópia, parcial ou total, deste documento, nos casos em que é legalmente admitida, deverá conter ou fazer-se acompanhar por este aviso.

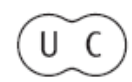




\title{
Museus e desenvolvimento local - o exemplo do Museu do Pão (Seia)
}

\author{
Marta Amado \\ Câmara Municipal de Seia. \\ matinha_amado10@hotmail.com

\section{Paulo Carvalho} \\ Departamento de Geografia e Centro de Estudos de Geografia e Ordenamento do Território (CEGOT). Faculdade de Letras da Universidade de Coimbra. \\ paulo.carvalho@fl.uc.pt
}

\section{Resumo:}

Os museus podem constituir instrumentos de uma rede coerente de estruturas, de recursos, de equipamentos essenciais no reforço de uma memória e identidade e na emergência de uma relevância geográfica, e assim contribuir para a construção de novos caminhos e o envolvimento de novos atores capazes de promover o desenvolvimento.

Com o intuito de analisar o modo como os espaços museológicos podem contribuir para revitalizar o território, melhorar a qualidade de vida dos residentes, reforçar a identidade local, captar novos visitantes e, deste modo, contribuir para o desenvolvimento local, enfatizamos o Museu do Pão (Seia), um investimento privado, inaugurado em 2002 (e que recebe mais de 100 mil visitantes/ano), e privilegiamos a apresentação e discussão de dados cedidos pelo Museu, bem como os resultados de inquéritos por questionário e entrevistas aos visitantes (no primeiro caso recorrendo à análise fatorial de correspondências múltiplas).

Palavras-chave: Museus. Desenvolvimento Local. Museu do Pão. Seia.

\section{Resumé:}

Musées et développement local - l'exemple du Musée du Pain (Seia)

Musées peuvent constituer des instruments pour un réseau cohérent de structures, les ressources, les équipement essentiel dans le renforcement d'une identité et mémoire et dans l'émergence d'une pertinence géographique et ainsi contribuer à la construction de nouvelles routes et l'implication de nouveaux acteurs capables de promouvoir le développement. Afin d'examiner comment les espaces du Musée peuvent contribuer à revitaliser le secteur, améliorer la qualité de vie des résidents, identité locale, attirer de nouveaux visiteurs et ainsi à contribuer au développement local, nous soulignons le Musée du Pain (Seia), un investissement privé, inauguré en 2002 (et recevoir plus de 100000 visiteurs par an), et de nous donner la préférence à la présentation et la discussion des données transférées par le Muséeainsi que les résultats des enquêtes par questionnaire et des entretiens aux visiteurs (dans le premier cas par analyse factorielle des correspondances multiples).

Mots-clés: Musées. Développement Local. Musée du Pain. Seia.

\section{Abstract:}

Museums and local development - the example of the Museum of Bread (Seia)

Museums may constitute instruments for a coherent network of structures, resources, essential equipment in strengthening of a memory and identity and in the emergence of a geographical relevance, and thus contribute to the construction of new roads and the involvement of new actors able to promote development. In order to examine how the Museum spaces can contribute to revitalize the area, improve the quality of life of residents, local identity, attract new visitors and thus to contribute to the local development, we emphasize the Museum of Bread (Seia), a private investment, inaugurated in 2002 (and receiving more than 100 thousand visitors/year), and we give preference to the presentation and discussion of data transferred by the Museum as well as the results of surveys by questionnaire and interviews to visitors (in the first case by factor analysis of multiple matches).

Keywords: Museums. Local Development. Museum of Bread. Seia. 


\section{Caminhos e contextos do desenvolvimento}

$\mathrm{Na}$ atualidade prevalece uma conceção de desenvolvimento alargada, segundo uma perspetiva multidimensional, com a valorização de dimensões inerentes aos domínios social (equidade), económico (eficiência), ambiental (sustentabilidade) e político (participação, parcerias e cooperação).

$O$ tipo de desenvolvimento que prevaleceu, regra geral, até ao final dos anos 70 do século XX, não considerava os limites ecológicos do crescimento económico e do próprio desenvolvimento, ignorando os riscos de degradação da natureza e o carácter limitado dos recursos naturais, assim como também não atendia às especificidades dos territórios e das populações, e aos mecanismos de participação e partilha de responsabilidade no exercício da gestão dos bens e interesses públicos.

É sobretudo a partir do início da década de 80 (século XX), que emerge uma renovação do conceito de desenvolvimento e, com este, novas formas de intervenção social.

As contradições (e o fracasso) do modelo de desenvolvimento economicista (produtivista), dominado por um poder técnico-económico centralizado, inspirado na filosofia do crescimento (de base industrial) a "qualquer preço" e na utilização incondicional dos recursos, conduziram a um conjunto de fracassos e desilusões sociais, nomeadamente a incapacidade de assegurar uma redistribuição equitativa da riqueza entre as regiões e as gerações; o aumento do desemprego e a crescente precarização das formas de emprego; o agravamento e alargamento das formas de pobreza e exclusão social; o aumento do número de "dependentes" nas sociedades modernas e os problemas ambientais (AMARO, 1998, citado em Carvalho, 2009).

Estes problemas, de carácter ainda mais significativo, uma vez que acompanham os processos de globalização económica e cultural, estão na génese da afirmação do papel ativo das comunidades locais na construção dos territórios e, afinal, de um novo paradigma expresso na ideia de desenvolvimento durável ou viável, inscrito no processo global de reestruturação das relações sócio-espaciais e de afirmação da especificidade dos territórios, que convém examinar concretamente à luz das estratégias e práticas dos atores locais.

A reestruturação do território, tributária de várias categorias de atores, segundo relações de hierarquia e poder é, então, marcada por duas lógicas espaciais diferenciadas. Por um lado, o modelo funcionalista, alicerçado nos imperativos do modo de produção fordista, comanda uma mobilidade de capitais, de bens e de pessoas, fortemente acelerada nos últimos anos. Por outro lado, o modelo territorialista valoriza os recursos e os valores humanos, as iniciativas e a criação de emprego local, participando no paradigma do desenvolvimento local (Carvalho, 2009).

0 desenvolvimento local pode ser entendido como a evolução de um território por meio de um processo de mobilização dos recursos endógenos nas dimensões território, património e população (VALLINA, 2002) ou como a "possibilidade das populações poderem expressar uma ideia de futuro num território visto de forma aberta e flexível, onde esteja ausente a noção do espaço como fronteira, concretizando ações que possam ajudar à (re)construção desse futuro" (FraGoso, 2005:64). Esta perspetiva de desenvolvimento local enfatiza a melhoria da qualidade de vida das pessoas, bem como o aumento da sua autoconfiança e organização tendo em conta principalmente os seus interesses e a sua participação.

Em síntese, afirma-se uma nova visão/cultura territorial e uma valorização do território como entidade de referência na definição de políticas de desenvolvimento, abrindo caminho a novas formas de participação e coordenação dos diversos atores na definição de objetivos, elaboração de estratégias e governação do território. Reconhecendo a especificidade de cada território e de cada contexto, pretende-se reduzir as desigualdades entre as unidades territoriais, em particular as disparidades em oportunidades de desenvolvimento (Carvalho, 2009).

Por outro lado, e atendendo ao seu carácter sobretudo endógeno e integrado, estas iniciativas teriam que se desenvolver como processos eminentemente coletivos e educativos, articulando-se com participação de intervenientes externos às comunidades e contextos locais envolvidos, que em estreita cooperação permitem a efetivação do seu desenvolvimento e das mudanças que se pretendem operar.

Às populações compete o papel de desenvolver ações que reforcem o tecido económico, social e cultural, local, nomeadamente através da reconstrução e valorização das memórias e identidades, o que explica o interesse e o desenvolvimento de processos museoló gicos a nível local.

Assim, a partir da recolha de património disperso e de testemunhos reunidos sobre a vida e a história do território e, em particular, das pessoas que a ele estiveram e estão ligadas, criam-se iniciativas ligadas à conceção de espaços museológicos que podem funcionar como polos de desenvolvimento. 


\section{Museus como instrumentos de desenvolvimento local}

O museu assume-se como instrumento de desenvolvimento local pela utilização do recurso endógeno "património", tendo como função a salvaguarda e valorização do património cultural de uma comunidade, desempenhando um papel social (AMADO, 2011).

"Hoje, não existe, por assim dizer, nenhuma localidade, cidade ou aldeola que não queira possuir um Museu, o que não está necessariamente ligado apenas ao desejo, aliás bem patente, de uma população em busca da sua história e da sua identidade regional" (Mendes, 1999: 25). É neste sentido que o museu é visto como um instrumento dinâmico que vem reforçar a identidade das comunidades ao contribuir para a salvaguarda de um património estimado por todos.

É um facto consumado que têm vindo a crescer os apoios às entidades museológicas por parte dos governos, das autarquias, empresas, e organismos responsáveis pela promoção do desenvolvimento. Estes apoios constituem uma mais-valia para a salvaguarda e divulgação de legados, que, sem intervenção museológica estariam condenados a desaparecer rapidamente.

No entanto é claro que o museu configura um elemento importantíssimo a considerar em políticas e estratégias de desenvolvimento, constituindo não só um valioso repositório de história e cultura, como também um agente dinâmico ao serviço da comunidade, na senda do progresso e desenvolvimento local. Por tudo isto, as estratégias de desenvolvimento de carácter integrado e sustentado, devem considerar os espaços museológicos como intervenientes patrimoniais que atuam no sentido do desenvolvimento dos contextos territoriais em que estão inseridos.

Para Primo (2000: 39), o grande desafio que se coloca no panorama dos museus é a sua capacidade de funcionar, por um lado, como instrumento de desenvolvimento pessoal e, por outro, como instrumento de desenvolvimento local. Para tal é necessário que os museus assumam que a sua intervenção se insere também na discussão e busca de solução dos problemas dos indivíduos enquanto pessoas e enquanto seres que fazem parte de uma coletividade; na interpretação e intervenção comunitária; na importância que assumem os processos de intervenção.

Também Moreira (2000: 3/4), afirma a estreita relação entre os museus e o desenvolvimento local. Segundo este autor, o nascimento de um museu local justifica-se por duas razões: para recolher e conservar as manifestações de um passado considerado importante enquanto referência do presente e guia do futuro; para promover o desenvolvimento pessoal e o desenvolvimento local. No primeiro caso estamos perante um museu-armazém, um museu com funções de conservatório, ao passo que no segundo caso estamos na presença de um museu entendido como ação, como processo. O museu local, de acordo com esta última ótica, como ação e como processo, é um instrumento de desenvolvimento que pode atuar em dois domínios: um domínio interno que visa diretamente a promoção do bem-estar, material e imaterial, da população da sua área de influência; um domínio externo que visa indiretamente a promoção desse bem-estar.

A renovação do panorama museológico nos últimos trinta anos reflete o alargamento das funções dos museus que passam de mera conservação para um uso social do património, com vista a um desenvolvimento da comunidade. 0 crescimento e a diversidade do universo patrimonial; a valorização e o papel central da paisagem enquanto matriz cultural; a abertura dos museus aos mais novos e a preocupação de os tornar espaços de fácil e didático contato com o passado; a forma dinâmica, agradável, aliciante de expor peças e materiais, com um fio condutor no percurso do visitante; a investigação da realidade cultural do território numa perspetiva de interdisciplinaridade, e o envolvimento das populações num processo conducente à sua promoção são as características mais expressivas da cisão com os cânones da museologia tradicional ( $\mathrm{C}_{\mathrm{AR}}$ VALHO, 2003).

Em contexto rural, os museus podem constituir elementos fundamentais na divulgação do respetivo património local, no qual se reflete e se encontra a história, a tradição e a imagem ancestral do mundo rural, onde os visitantes possam perceber como se trabalhou e viveu naqueles lugares, o que se produziu, as histórias que se contavam, as tradições das gentes. Estes espaços não só se inscrevem num esforço de reificar o passado, antes afirmam um território e dinâmicas que contribuem para o presente e para o futuro e, nesse sentido, participam amplamente na reflexão sobre o desenvolvimento (AMADO, 2011).

Neste sentido, o museu poderá constituir um instrumento privilegiado de descoberta ou de reinvenção das vias e das formas de intervir no desenvolvimento, promovendo a atividade dos artesãos, a produção, a venda, a manutenção de um saber-fazer, a criação de riqueza, ou articulando-se com algumas intervenções no território, ao nível dos parques naturais, paisagens ou manutenção de equipamentos (BRITo, 2004). 


\section{Panorama museológico em Portugal}

Como refere AMADO (2011), o entendimento do conceito de museu não é transversal a todas as instituições que compilam e divulgam informação sobre a realidade museológica em Portugal. Este facto, aliado a metodologias distintas no que se refere à recolha de informação, leva a disparidades numéricas bastante significativas.

Tomando como exemplo o ano de 2000, basta referir que o Instituto Nacional de Estatística, nas Estatísticas da Cultura, apresenta a existência de 201 museus, ao passo que o Observatório das Atividades Culturais, na sua publicação "Os Museus em Portugal no período 2000-2005: Dinâmicas e Tendências", refere 533 entidades museológicas. Esta última entidade, em publicação anterior denominada "O Panorama Museológico em Portugal, 2000-2003", refere 491 museus para o mesmo ano em análise.

A importância do museu em Portugal verifica-se na aprovação da Lei-quadro dos Museus Portugueses (Lei $n^{\circ}$ 47/2004 de 19 de Agosto) e na sua filosofia. Neste diploma afirma-se que "cada Museu efetua o estudo e a investigação do património cultural afim à sua vocação" (artigo 9, $2^{\circ}$ ). Outro ponto interessante é o ponto 3 do artigo $9^{\circ}$, no qual se afirma: "A informação divulgada pelo Museu, nomeadamente através de exposições e edições, da acção educativa e das tecnologias de informação, deve ter fundamentação científica".

Segundo as estatísticas oficias, o número de museus em Portugal tem aumentado significativamente. No ano de 2000 existiam em Portugal 201 museus $^{1}$ (Figura 1) passando para 363 em 2009, o que se traduz num acréscimo de cerca de $80 \%$.

Considerando os quantitativos referentes aos visitantes, encontramos uma tendência paralela no sentido do seu incremento progressivo ao longo do tempo, tendência espectável na medida em que existe uma relação entre a presença de instituições e as visitas.

Uma leitura mais detalhada do gráfico que expressa a evolução anual dos visitantes nos museus portugueses (Figura 2) revela o papel crescente destas instituições no nosso país, uma vez que os museus portugueses receberam em 2000 um total de 7.367.576 visitantes e em 2009 o número aumentou para 12.931 .846 visitantes. Importa ainda destacar duas quebras na

${ }^{1}$ Os valores apresentados correspondem aos museus que, no ano de referência, cumpriam os seguintes critérios: existência de, pelo menos, uma sala ou um espaço de exposição; abertura ao público, permanente ou sazonal; existência de, pelo menos, um conservador ou um técnico superior (incluindo pessoal dirigente); existência de um orçamento e existência de um inventário.

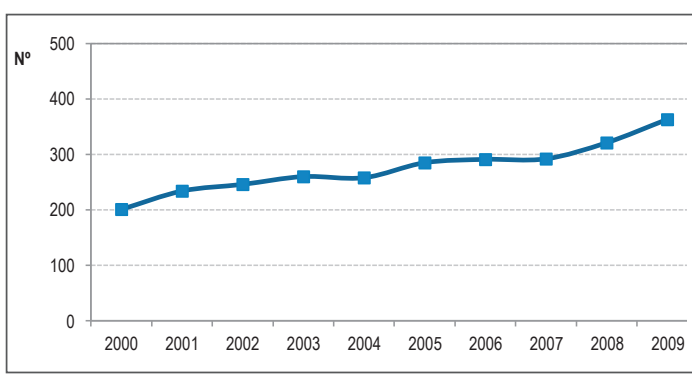

Figura 1

Evolução do número de museus em Portugal, entre 2000 e 2009.

Fonte: INE, Anuário Estatístico de Portugal e Estatísticas da Cultura, 2009.

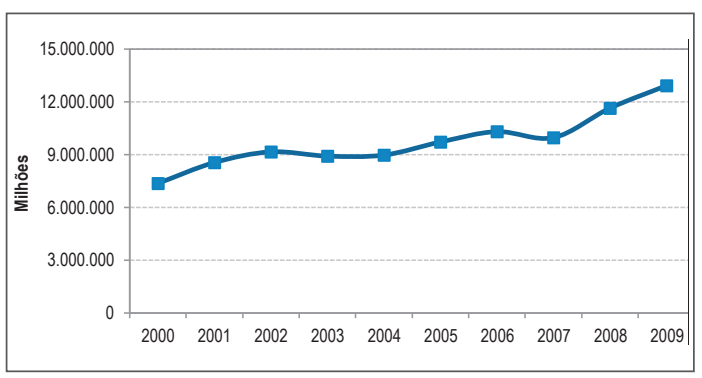

Figura 2

Evolução do número de visitantes dos museus em Portugal, entre 2000 e 2009

Fonte: INE, Anuário Estatístico de Portugal e Estatísticas da Cultura, 2009.

tendência ascendente: uma, registada em 2002/2003 com uma redução no número de visitantes de $-2,63 \%$ e a outra verificada no período 2006/2007 com um decréscimo de $-3,34 \%$.

Os 363 museus contabilizados em 2009 perfazem um total de 12,9 milhões de visitantes, sendo que $26,2 \%$ dirigem-se aos Jardins Zoológicos, Botânicos e Aquários (Figura 3), 22,1\% a Museus de Arte, 16,8\% a Museus de História, 10,7\% a Museus Especializados, 5,9\% repartidos pelos Museus de Ciência e de Técnica e pelos Museus Mistos e Pluridisciplinares, seguindo-se com percentagens inferiores os Museus de Arqueologia (4,9\%), Museus de Território (3,2\%), Museus de Etnologia e Antropologia $(2,3 \%)$, Museus de Ciências Naturais e História Natural $(1,9 \%)$ e Outros Museus $(0,1 \%)$.

Tal como referimos anteriormente, existe uma discrepância significativa entre os dados relativos aos Museus publicados pelo INE e os que o Observatório das Actividades Culturais utiliza tendo por fontes a base de dados "Museus".

Dado que pretendemos uma caracterização mais detalhada da realidade museológica portuguesa, foi necessário optar por uma das fontes como suporte para a referida análise. Assim, por uma questão de abran- 
gência do universo e por entendermos que os dados do OAC (Observatório das Actividades Culturais) dão melhor conta da realidade dos Museus locais, serão estes últimos os utilizados.

De acordo com Neves e SAntos (2006), em 2005 existiam registados na Base de Dados "Museus" 1018 museus em funcionamento, 326 em projeto, 93 em intenção e 39 fechados. Importa referir o interesse que os museus portugueses continuam a despertar no público investidor, já que, para um universo de pouco mais de mil atuais, se registam 419 em projeto, sendo a autoria da administração local (cerca de 60\%).
Contudo, é de ter em linha de conta que dos 920 museus abertos ao público, 298 só o fazem esporadicamente, aquando de visitas programadas. Este facto poderá ser explicado pela ausência de capital, uma vez que os investimentos em infraestruturas surgiram apoiados pelos fundos europeus, mas os investimentos em manutenção, nomeadamente em pessoal ao serviço escassearam para a sua abertura em regime permanente.

No que diz respeito aos museus segundo as tutelas observa-se o predomínio da administração local $(40,9 \%)$ e dos privados $(38,5 \%)$. Com valores mais reduzidos seguem-se a administração central $(16,7 \%)$ e, de

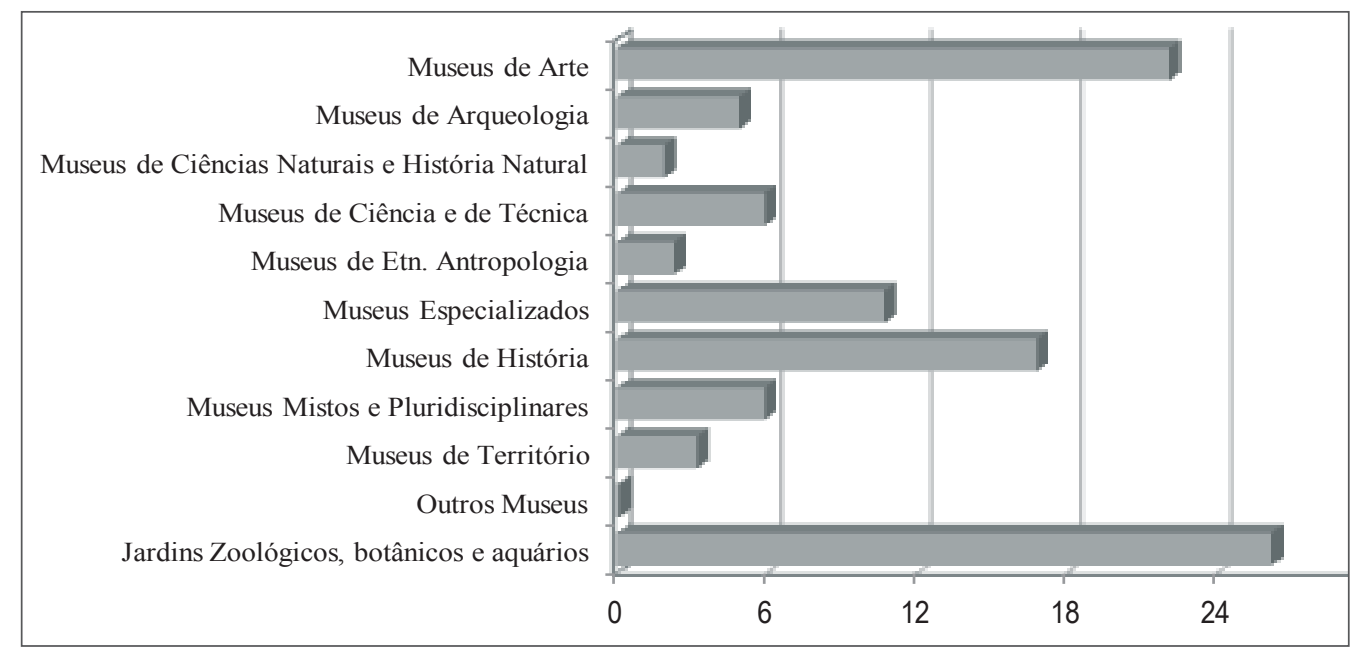

Figura 3

Visitantes, por tipologia de museus, jardins zoológicos, botânicos e aquários, em 2009.

Fonte: INE, Estatísticas da Cultura 2009.

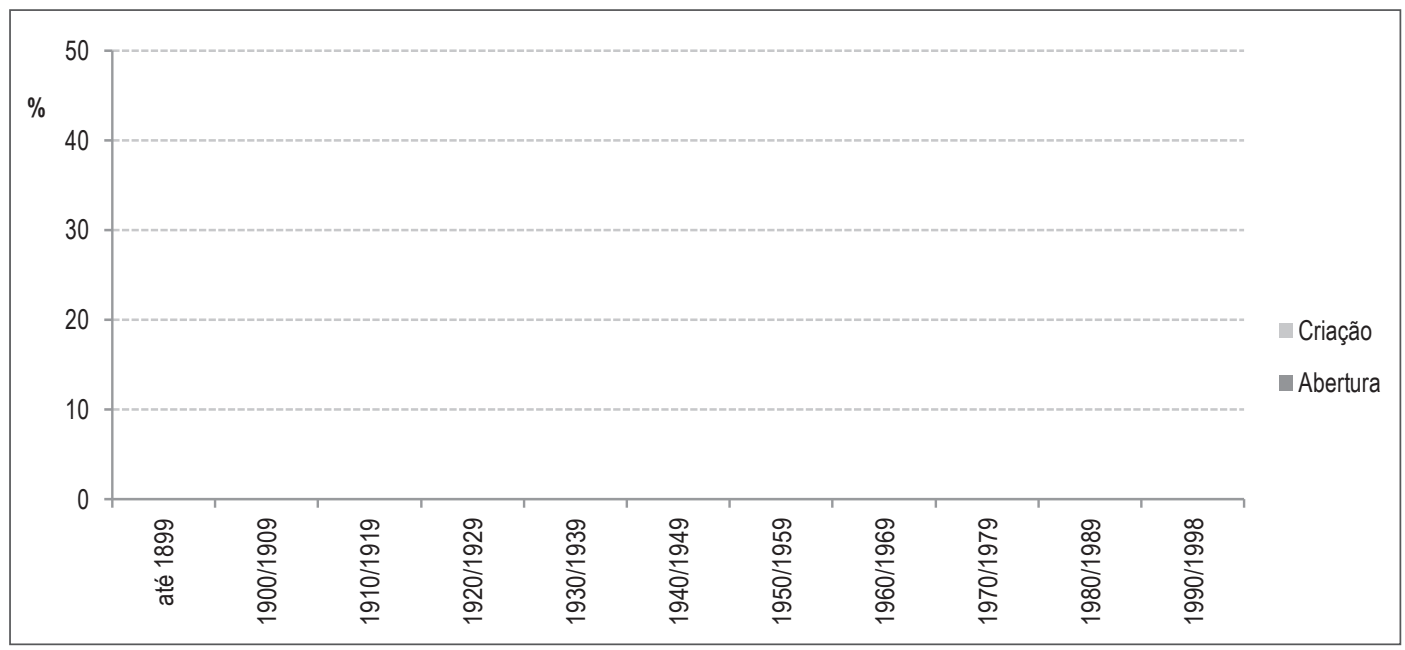

Figura 4

Criação e abertura dos museus em Portugal, por décadas.

Fonte: IPM/OAC. 
acordo com o significado regional do País, a administração regional (3,9\%).

Relativamente à administração local enquanto nível tutelar destacam-se as câmaras municipais $(88,9 \%)$, facto que está intimamente relacionado com a disponibilidade de verbas aplicadas aos Museus e com as suas funções de comunicação e ação.

No que se refere aos museus de tutela privada, 75,6\% manifestam fins não lucrativos, destacando-se as associações (37\%), as fundações $(16,8 \%)$ e a igreja $(15,1 \%)$, embora esta última esteja a perder importância ao longo dos tempos. Importa ainda destacar o peso que as empresas privadas têm vindo a adquirir na categoria de instituições que visam o lucro $(14,7 \%)$.

Tal como seria de esperar a tipologia de museus portugueses em 2005, aponta para a predominância dos Museus de Arte $(20,6 \%)$ e de Etnografia e Antropologia $(19,3 \%)$, imediatamente seguidos dos Museus Mistos e Pluridisciplinares (14,9\%) e os Especializados (10,7\%).

Quanto à data de criação dos museus por décadas constata-se que o crescimento dos museus portugueses foi muito relevante nas décadas de 80 e 90 (Figura 4), as quais conjuntamente perfazem cerca de $58 \%$ do total. No entanto, este crescimento já seria expectável na medida em que a década de setenta registaria uma percentagem significativa de $9 \%$, uma vez que os 46 Museus então fundados quase dobraram os 26 criados na década anterior.

Quando comparamos a data de criação com a data de abertura (Figura 4), constata-se que para a década 90 abriram $(35,7 \%)$ significativamente mais museus dos que aqueles que foram criados $(28,5 \%)$.

No que concerne à distribuição geográfica, é na Região de Lisboa que se verifica a implementação de cerca de $30 \%$ dos museus, seguindo-se a Região Norte (25\%) e a Região Centro $(18,4 \%)$, facto que poderá ser justificado pelo peso populacional de cada uma das regiões.

\section{Museu do Pão}

\subsection{Características e dinâmicas territoriais de Seia/Serra da Estrela}

O Museu do Pão localiza-se em Seia (na vertente ocidental da Serra da Estrela). O Município de Seia (Figura 5) ocupa uma área de $436 \mathrm{~km} 2$ (o que corresponde a $50 \%$ da área da Sub-região da Serra da Estrela)

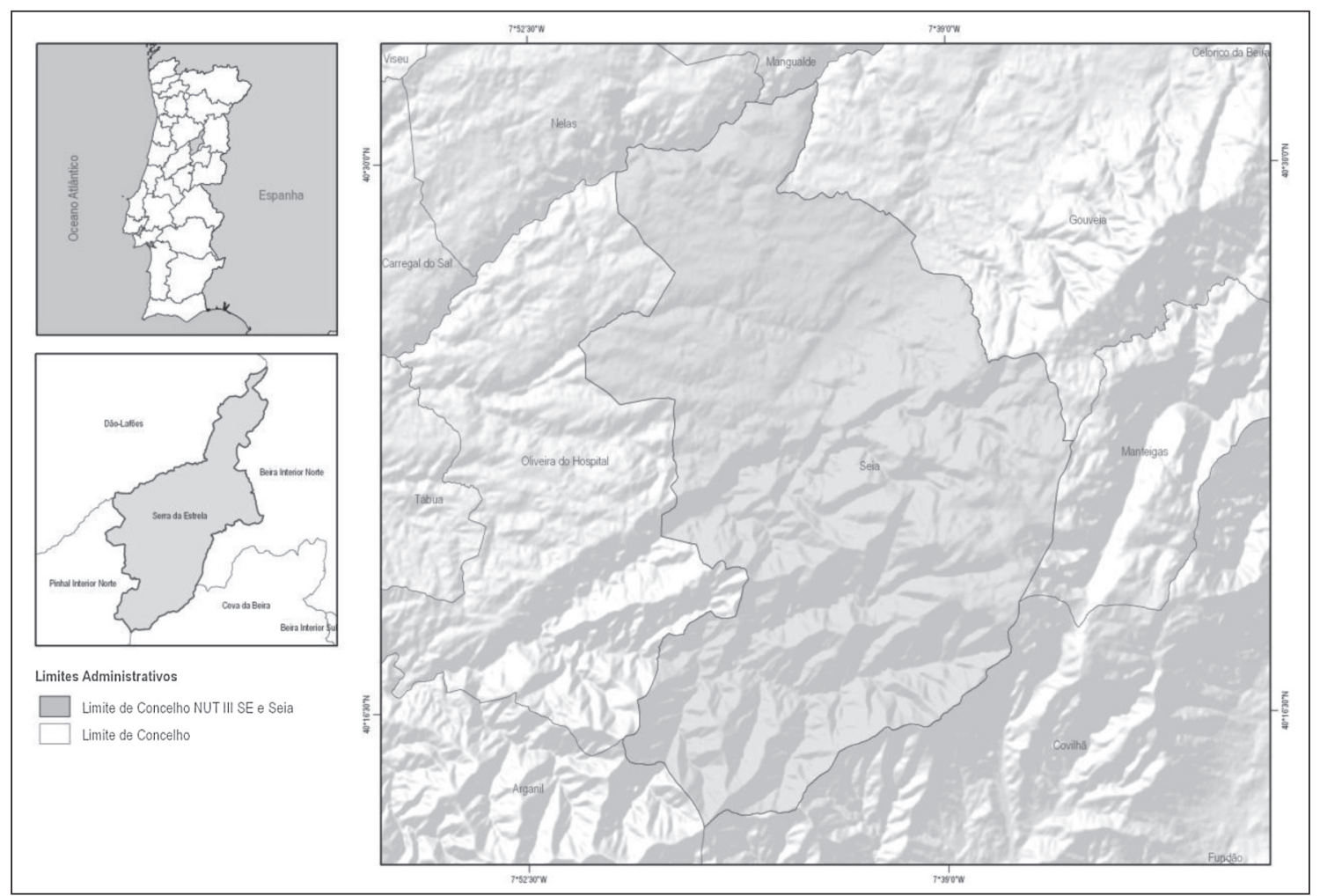

Figura 5

Localização e enquadramento administrativo do Município de Seia.

Fonte: AMADO, 2011. 
e apresenta do ponto de vista físico, um evidente contraste entre o sector Meridional e Setentrional. Assim, a Sul, no limite entre as Serras da Estrela e do Açor, domina uma paisagem muito acidentada e de vertentes abruptas, com altitudes compreendidas entre 300-1100 metros, caracterizada por uma rede hidrográfica densa e de traçado muito sinuoso. Por seu turno, a Norte, destaca-se a depressão tectónica designada de "bacia de Seia", que se estende desde o Sopé da Serra da Estrela até ao Vale Médio do Mondego e, que em alguns sectores apresenta um abatimento de 50 metros relativamente aos níveis médios desta plataforma. Ainda na metade Setentrional, a Oriente, o relevo apresenta-se constituído por um conjunto de plataformas desniveladas, que traduzem a génese tectónica da Serra da Estrela, e que alcançam uma altitude máxima de 1993 metros no planalto da Torre (AMADO, 2011).

A rede viária do Município de Seia encontra-se intimamente ligada aos condicionalismos físicos do próprio território, bem como da região envolvente. Uma análise atenta à morfologia do município permite observar uma distribuição bastante heterogénea dos declives, com o predomínio das classes mais elevadas, o que tem vindo a condicionar a implementação das infraestruturas viárias, bem como o seu traçado, afetando deste modo a mobilidade. Importa referir que o Município de Seia não é servido diretamente por autoestrada, nem por itinerários principais ou complementares, pelo que é apenas através da EN17 e da EN231, localizadas no sector Norte do Município, que se efetua a ligação à A25, a qual, em termos regionais, liga Aveiro a Vilar Formoso. Ao nível interno verificamos uma menor densidade da rede viária no sector montanhoso, devido aos condicionalismos impostos pelos forte declives, em oposição ao sector mais aplanado, onde a densidade da rede vária é maior, garantindo uma maior mobilidade populacional (AMADO, 2011).

Em relação à população residente, verificamos que entre 1981 e 2011, o Município de Seia perdeu 6705 habitantes $(-21,2 \%)$, num processo que foi iniciado em meados da centúria, facto que poderá ser justificado pela mobilidade interna para os centros urbanos mais próximos e também pela emigração. Este decréscimo afeta quase todas as freguesias, embora de forma mais intensa as que estão localizadas no sector Meridional.

A distribuição espacial da população revela um padrão territorial polarizado sobretudo pelas freguesias urbanas de Seia e São Romão e pelas freguesias de Paranhos e Tourais, localizadas na metade norte do Município.

Por outro lado, é evidente a crescente diminuição das classes mais jovens e o subsequente aumento das classes mais idosas, o que contribui para a crescente tendência de envelhecimento da população. Os valores do índice de envelhecimento refletem esta evolução uma vez que o total da população passou de $86,1 \%$ em 1991 para 151,0\% em 2001 (AMAdo, 2011).

No que concerne aos sectores de atividade económica, e numa análise comparativa entre os anos de 1991 e 2001, é possível identificar um decréscimo dos sectores primário e secundário, passando dos $11 \%$ para os $5 \%$ e dos $54 \%$ para os $45 \%$, respetivamente. Relativamente ao sector terciário verificou-se um acréscimo bastante expressivo, passando dos 34\% em 1991, para os $50 \%$ observados no ano de 2001.

\subsection{Espaço museológico e visitantes}

O Museu do Pão (Figura 6) encontra-se sediado na Quinta Fonte do Marão, num edifício recuperado e ampliado para o efeito, com uma área de aproximadamen-

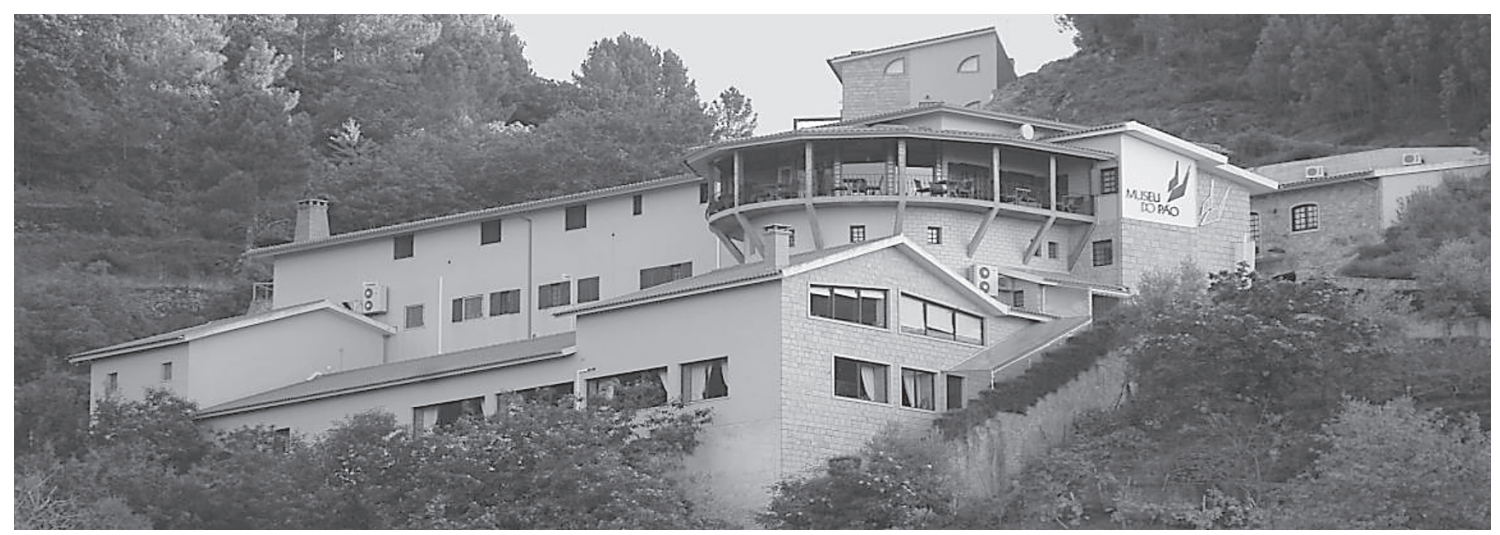

Figura 6

Museu do Pão

Fonte: AMADO, 2011. 
te $3.500 \mathrm{~m} 2$. Esta iniciativa teve a sua génese em 1996, através de um grupo de professores e empresários com bastante interesse pela gastronomia tradicional serrana, que durante os seis anos seguintes reuniram todo o espólio e edificaram o espaço Museu.

Trata-se de um complexo museológico de entidade privada, inaugurado a 26 de Setembro de 2002, dotado de quatro salas expositivas. A sala "O Ciclo do Pão" constitui o espaço que abre o percurso expositivo, na qual se recria o ciclo tradicional do pão português, desde a terra, a eira, o moinho, a casa, o forno bem como as respetivas alfaias e instrumentos utilizados. Um ciclo antigo que se revive através de 14 painéis explicativos de cada passo da produção do pão. A reconstituição de uma antiga padaria e de três moinhos em constante funcionamento são um tributo à sua importância secular, mas agora praticamente extintos.

A evolução política e social de questões relacionadas com o pão em Portugal, desde 1640 (Restauração da Independência) até 1974 (Restauração da Democracia), apresentada em cerca de 350 documentos históricos, que vão desde editais a cartas régias, de folhetos publicitários a cartazes, cartas, panfletos ou senhas alimentares, bem como o pão associado à religião, à fé: o pão místico e simbólico, são outras das mais-valias expostas neste espaço museológico (AMADo, 2011).

Na sala "A Arte do Pão" o visitante poderá observar como o pão e os seus cereais panificáveis serviram como fonte de inspiração artística, através da produção de azulejaria, cerâmica, filatelia, artes decorativas, vidro, artes gráficas, fotografia, entre outros.

Por outro lado, constitui-se como espaço lúdicodidático, com uma forte componente interativa, através da recriação do ciclo do pão e da sua feitura. Esta sala contempla ainda uma secção pedagógica dedicada aos mais novos, onde podem tocar na massa, fazer as suas formas e vê-las crescer e cozer num forno tradicional a lenha.

O espaço Museu para além da dimensão expositiva compreende um conjunto de serviços que coloca à disposição dos visitantes e da população local, nomeadamente bar-biblioteca, uma mercearia antiga, um restaurante e uma padaria. 0 bar-biblioteca para além de um espaço de lazer é também considerado um espaço de cultura, onde se desenvolvem frequentes atividades culturais, nomeadamente tertúlias temáticas.

Este espaço museológico é ainda considerado um local que recria as vivências e costumes das velhas mercearias de aldeia, onde se dá a conhecer os pães produzidos pelo Museu, bem como os produtos locais, que fazem a alegria de quem visita.

O Restaurante assume-se como um verdadeiro Centro de Investigação Gastronómica, que redescobre e recria os sabores únicos desta terra, contribuindo de certa forma, para atração de diferentes públicos.

Trata-se de uma unidade museológica muito bem organizada, com uma grande capacidade no domínio da informação prestada aos visitantes, que pretende dar a conhecer a "História do Pão", desde as formas de cultivo, passando pelas técnicas tradicionais de moagem, produção e distribuição, as quais se encontram em vias de extinção.

No que diz respeito à evolução anual do número de visitantes do Museu do Pão, desde 2003 a 2010 (Figura 7), observa-se um decréscimo de $-19,05 \%$ dos visitantes, com a passagem dos 115190 aos 92717 visitantes. De destacar o ano de 2004 como o mais próspero para o complexo museológico, com 124514 visitantes, seguindo-se o ano de 2007 com 117700 entradas. Importa ainda referir que embora os restantes anos em

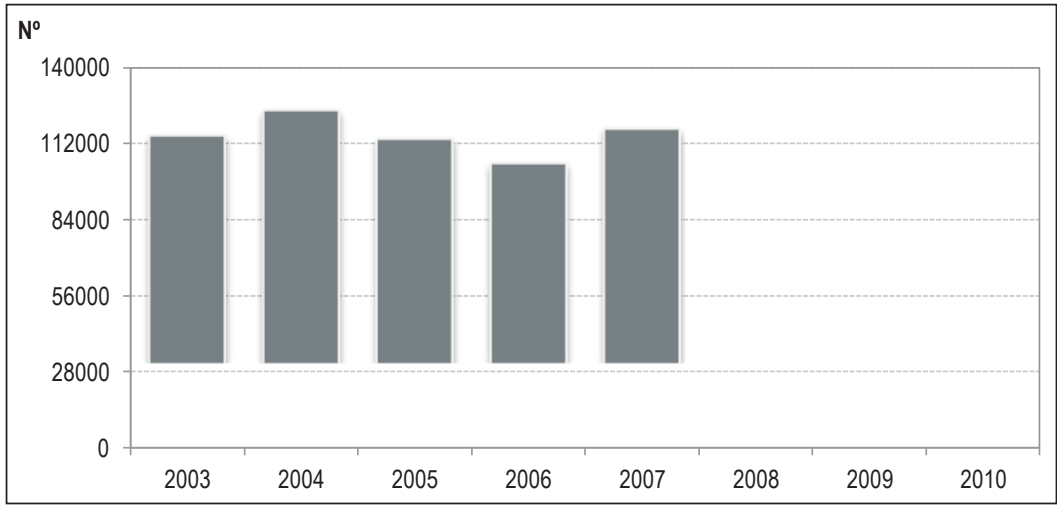

Figura 7

Distribuição anual do número de visitantes do Museu do Pão, de 2003 a 2010.

Fonte: Base de dados do Museu do Pão. 
análise assinalem quebras face a 2004, somente os anos mais recentes, nomeadamente 2009 e 2010 apresentam um número de visitantes inferiores aos 100 mil, respetivamente 92366 e 92717 visitantes.

Anualmente são os meses de Fevereiro, Março e Abril que assinalam o maior número de visitantes, com um total de $34,75 \%$ dos visitantes $(10,86 \%, 12,59 \%$ e $11,29 \%$ respetivamente), seguindo-se a estes, embora com menores quantitativos, os de Agosto e Dezembro com designadamente $10,27 \%$ e $8,80 \%$. A chegada da Primavera a 21 de Março, a qual se caracteriza por temperaturas mais amenas face ao Inverno, a que se associa a dinamização de múltiplas atividades escolares, tais como as comemorações do dia da Árvore e da Criança, as férias de Carnaval e da Páscoa, são alguns dos fatores explicativos da maior procura deste espaço museológico. No mês de Agosto, a crescente procura explica-se, não só, pelo regresso temporário dos emigrantes portugueses residentes no estrangeiro, mas também, devido à preferência pela natureza, pela paisagem de muitas famílias, para desfrutar das sua férias de Verão, trocando o turismo balnear pelo melhor que a montanha tem para oferecer. No que se refere ao mês de Dezembro, apesar de não apresentar valores tão elevados, face aos anterior referidos, evidencia uma importante procura, facto que poderá ser justificado pela presença de neve, em associação com a celebração do Natal e a passagem do Ano que motiva a deslocação ao Maciço Central e, com isto, uma maior afluência ao Museu (AMAdo, 2011).

Semanalmente, é ao Sábado e, em particular, ao Domingo que a procura é maior, concentrando-se nos fins-de-semana cerca de $47 \%$ dos visitantes. Nos restantes dias da semana, a distribuição é bastante equitativa, recebendo este espaço museológico entre 9 e 12\% dos totais anuais.

Relativamente à proveniência dos visitantes do Museu do Pão verificamos que a esmagadora maioria, com um valor percentual de $95 \%$, é de origem nacional. Os restantes $5 \%$ são estrangeiros, maioritariamente espanhóis brasileiros, franceses, dinamarqueses e holandeses. Estes resultados perfilam-se com os obtidos por FERNANDES (1998), quando procedeu à caracterização dos turistas que afluem à Serra da Estrela, considerando que, em termos de origem geográfica, se verifica o domínio avassalador do turista português.

No que concerne à classificação dos visitantes, mais de metade surge de forma individual ou em família (58\%), enquanto os grupos, onde se incluem excursões e também visitas escolares, representam 35\% das entradas totais, desde 2003. Importa ainda referir que $7 \%$ dos visitantes não pagam para visitar este espaço museológico, uma vez que se tratam de acompanhantes destes grupos, nomeadamente docentes e pessoal responsável destes grupos.

\subsection{Perfil dos visitantes, perceção do Museu e avaliação da visita}

No sentido de perceber a expressividade do Museu do Pão a nível nacional, bem como o seu contributo para o desenvolvimento local procedeu-se à realização de um inquérito por questionário aos visitantes, cuja execução decorreu entre 1 de Fevereiro a 31 de Agosto de 2011, uma vez que este período corresponde a $69,01 \%$ do número total de visitantes/ano contabilizados entre 2003 e 2010.

A metodologia aplicada teve como base a tabela estatística de definição do tamanho da amostra de ABREU (2006), tendo como referência o fluxo de visitantes entre 2003 e 2010, que perfaz uma média de 108852 visitantes/ano. De acordo com este autor, o tamanho da amostra é determinado em função da variabilidade da característica e do grau de precisão pretendido. A variabilidade é expressa pelo Coeficiente de Variação, que relaciona o desvio padrão com a média aritmética. 0 grau de precisão tem duas componentes, a maior diferença aceitável (D) entre o valor estimado a partir da amostra e o valor verdadeiro da população e a medida de confiança $(K)$ em que o valor estimado esteja dentro do intervalo representado por +/- D (utiliza-se um intervalo de confiança de $95 \%$ ou $99 \%$ ). Neste caso optou-se por um valor de confiança de $95 \%$ e por um coeficiente de variação de 0,2 , pelo que a dimensão da amostra deve ser de 96 indivíduos. Assim, durante o período de investigação foram inquiridos 96 indivíduos, com idades superiores a 18 anos e que se deslocaram de forma individual.

0 inquérito realizado apresenta um total de 23 questões, as quais se encontram divididas em três grupos principais, a saber: 1. caracterização dos inquiridos, designadamente o sexo e a idade dos visitantes, nacionalidade, o concelho de residência, as habilitações literárias e a profissão; 2 . perceção que os visitantes têm do Museu, através de um conjunto de questões relacionadas com frequência e os motivos da visita, a divulgação do Museu, bem como o grau de importância na preservação da atividade desenvolvida pelo Museu; 3. análise e avaliação da visita, que pretende dar a conhecer os espaços visitados pelos inquiridos dentro do espaço museológico, a duração da visita, a companhia do visitante, assim como as principais impressões (positivas e negativas) e, ainda, uma análise sobre os serviços prestados pelo Museu e as opiniões expressas pelos inquiridos (AMADO, 2011). 
Os principais resultados do inquérito, no que diz respeito ao grupo 1, são os seguintes: $36 \%$ dos inquiridos tinham idades inferiores a 30 anos, 44\% dos indivíduos apresentavam entre 30 e 49 anos, e apenas 11\% apresentavam mais de 60 anos; $97 \%$ dos visitantes são de nacionalidade Portuguesa; acentuada dispersão geográfica, com cerca de 45 municípios assinalados - o maior fluxo de visitantes provém da Região Centro (63\%), sendo de destacar os Municípios de Aveiro (9\%) e Seia (6\%) como os mais representativos; grande diversidade nas qualificações dos visitantes, embora com maior preponderância do Ensino Superior (54\%) - o Ensino Secundário e o Ensino Básico representam 23\% e $22 \%$ dos visitantes, respetivamente; a estrutura sócio-profissional revela a importância dos trabalhadores por conta de outrem, com 35\% do total, seguindo-se os funcionários públicos (16\%), os reformados (13\%) e trabalhadores por conta própria (11\%), que assim perfazem $75 \%$ das respostas dos inquiridos.

Em relação às questões do grupo 2 , os resultados permitem evidenciar que $65 \%$ dos inquiridos efetuaram a visita pela primeira vez e, por conseguinte, $35 \%$ dos visitantes já conheciam o Museu do Pão (destes, 53\% efetuaram a sua visita num intervalo de tempo superior a 1 ano).

Conhecer o principal destino dos inquiridos torna-se fundamental para compreender a capacidade de atração deste espaço museológico. Neste sentido, cerca de $68 \%$ dos inquiridos afirmam que apesar da passagem pelo Museu do Pão, este não foi o principal destino da sua viagem, contrapondo-se aos restantes $32 \%$ dos visitantes para quem o Museu do Pão foi o principal destino da visita. Deste modo, existem um conjunto de lugares de interesse que os visitantes planearam conhecer após a sua visita ao Museu do Pão. A Região da Serra da Estrela é o principal destino a visitar pelos inquiridos (51\%), destacando-se a Torre e a Serra da Estrela, com $23 \%$ e $12 \%$, respetivamente. Importa referir também as estruturas municipais com $39 \%$ do total, sendo de salientar o Museu do Brinquedo (19\%) e o Centro de Interpretação da Serra da Estrela (CISE) com 14\% como os mais representativos; a visita às Aldeias Históricas, nomeadamente Piódão (5\%) e Linhares da Beira (2\%), bem como a passagem pela aldeia de Folgosinho e pela vila de Manteigas, com 1,75\%, cada, representam opções de visita com menor relevância. Apesar de não ser considerado o principal destino dos inquiridos, o Museu do Pão beneficia de uma excelente localização geográfica (situando-se nas imediações de um dos principais eixos de acesso ao planalto superior), constituindo uma maisvalia no escasso conjunto de ofertas culturais, a todos quanto visitam este espaço serrano.
Dos inquiridos que se deslocaram ao Museu do Pão, verificamos que $66 \%$ foram recomendados por alguém, $14 \%$ obtiveram conhecimento através de publicidade e 5\% referiram a Escola, Associação ou Faculdade como principal meio de comunicação (e o valor percentual foi referido para a internet).

Relativamente aos motivos que prevalecem na escolha deste espaço museológico destaca-se a proximidade à Serra da Estrela (39\%), seguindo-se a gastronomia $(16 \%)$ e a atração ao turismo de neve e de paisagem (13\%). Com valores menos representativos, mas ainda assim significativos, destaca-se a grande motivação em conhecer a temática que o Museu desenvolve, nomeadamente o retrato do ciclo tradicional do pão português ( $8 \%)$, seguindo também a ocupação do tempo (8\%) e, por fim, de destacar as atividades didáticas que - Museu do Pão oferece às crianças e famílias (8\%).

$\mathrm{Na}$ opinião de $47 \%$ dos inquiridos, o Museu do Pão contribui para a conservação de saberes e valores tradicionais que trazem valor acrescido à cidade e, ainda, reconhecimento e valorização do Museu a nível nacional e internacional (25\%). De destacar ainda que $17 \%$ dos inquiridos refere que a preservação desta atividade é fundamental para as crianças e a sua preservação contribui para promover a vertente pedagógica. De facto, todo o Museu se apresenta como um espaço pedagógico de excelência, onde se pretende dar a conhecer a todos os visitantes os métodos, técnicas e utensílios na produção do pão em Portugal, bem como permitir aos mais jovens a possibilidade de interagir em todo o processo de transformação. Importa ainda referir que $11 \%$ dos visitantes destaca a importância na preservação desta atividade, na medida em que contribui para o desenvolvimento do local e divulgação dos seus produtos.

No que diz respeito à terceira parte do inquérito, cujo objetivo é caracterizar a visita, destaca-se a elevada percentagem de inquiridos que visita o Museu do Pão ao fim-de-semana, com $83 \%$ do total e apenas $17 \%$ surge durante a semana. Quando analisamos o tempo de duração da visita, constatamos que $36 \%$ dos visitantes permaneceu um período considerável neste espaço museológico, nomeadamente entre 30 minutos a 1 hora (36\%) e entre 1 hora e 2 horas (35\%) para fazer a sua visita. De igual modo, a leitura dos resultados permite afirmar que a família constitui a principal preferência do visitante no seu percurso até ao Museu, com um total de $56 \%$, seguindo-se a companhia dos amigos, embora com expressão mais reduzida (34\%).

De um conjunto alargado de espaços que o Museu do Pão oferece destacam-se as salas expositivas como lugar preferencial de passagem aquando da visita, com 
valores na ordem dos $90 \%$. Com percentagens intermédias destacam-se o Bar-Biblioteca e a Mercearia, com $73 \%$ e $71 \%$, respetivamente. A gastronomia não é de facto o principal motivo de vista a este Museu, facto comprovado com apenas $56 \%$ das visitas ao restaurante. Por fim o espaço menos frequentado pelos visitantes é a Padaria, com 51\%.

Para compreendermos a relação dos visitantes com o Museu, foi nosso objetivo recolher a opinião dos inquiridos em relação ao que mais gostaram e ao que menos gostaram na sua visita. Quanto ao que mais gostaram foram referidos 58 elementos dos quais se destacam as salas expositivas (24\%), as tradições $(7 \%)$ e a gastronomia (6\%). Os aspetos negativos durante a visita foram enunciados por apenas $22 \%$ dos visitantes, sendo as acessibilidades o principal problema enunciado, com $10 \%$ do total; o estacionamento, o exterior, a sinalética e guias que falem outras línguas são outros dos problemas assinalados pelos inquiridos.

Para além da identificação dos principais problemas e potencialidades deste espaço museológico foi nosso objetivo questionar os visitantes a respeito dos serviços prestados. A opinião dos inquiridos é unânime no sentido de considerarem que o Museu apresenta um conjunto de serviços de boa e muito boa qualidade que promovem uma maior visibilidade deste espaço. A avaliação apresentada pelos inquiridos foi boa e muita boa em praticamente todos os serviços, nomeadamente no pessoal, iluminação, limpeza, horário, segurança e tranquilidade, qualidade dos artigos da mercearia, qualidade do restaurante e instalações sanitárias. Em relação a outros serviços, tais como, estrutura do Museu, informação e explicação das salas, sinalética, divulgação do Museu e preços dos bilhetes, a avaliação reparte-se entre o razoável e o muito bom. A área na qual os visitantes demonstram um enorme desagrado refere-se aos acessos, como já foi referido anteriormente. Assim, 49\% dos inquiridos refere que as acessibilidades são más, na medida em que o pavimento é irregular e o acesso ao Museu após a saída da Estrada Nacional 339 apresenta um troço muito estreito, que impede o cruzamento entre dois veículos.

0 inquérito termina com uma questão importante que pretende analisar a opinião do visitante acerca deste espaço museológico. Assim, em função dados obtidos constatamos que $30 \%$ dos inquiridos refere que o Museu do Pão desenvolve um forte papel educativo e $29 \%$ indica que este espaço contribui para o desenvolvimento local. De facto estas duas opiniões complementam-se pois estas iniciativas de recuperação e revalorização das identidades locais, por um lado, transmitem conhe- cimentos ancestrais sobre a história local, usos, modos de vida e tradições, principalmente ao público juvenil que a partir destas iniciativas têm possibilidade de conhecer os métodos, técnicas e utensílios utilizados na produção do pão e, por outro, contribuem para o desenvolvimento local na medida em que atraem milhares de visitantes e consequentemente potencia o desenvolvimento das unidades turísticas de apoio ao turismo na cidade. Ainda, $24 \%$ dos inquiridos refere que se trata de uma instituição com grande atratividade turística, facto ligado ao concelho e à Região da Serra da Estrela.

Com percentagens inferiores, mas ainda assim merecedoras de análise, $15 \%$ dos inquiridos salienta o facto de ser uma instituição ao serviço da comunidade. O Museu do Pão constitui-se como fonte de criação de emprego, especialmente para as populações que residem nestas áreas serranas, pois a maior parte dos trabalhadores são oriundos do respetivo concelho. Por outro lado, a presença de uma pequena loja com produtos tradicionais e de um restaurante, onde se recuperam os sabores tradicionais da gastronomia serrana, permite a dinamização e o escoamento dos produtos locais, constituindo também, nestas circunstâncias, um fator de criação de emprego a montante.

Em suma, o vasto conjunto de ofertas que este espaço museológico coloca aos dispor dos visitantes e da comunidade local, contribui para o seu desenvolvimento através das atividades que proporciona, sejam elas de cariz educacional ou cultural, cria emprego, contribui para a promoção dos produtos locais e consequentemente gera fluxos de pessoas e bens, constituindo assim uma mais-valia para o tecido económico desta área serrana.

De modo geral poderemos afirmar que $51 \%$ dos inquiridos ficou muito satisfeito com a visita ao Museu do Pão, 47\% ficou satisfeito e apenas uma percentagem residual de indivíduos (2\%) referiu que ficou pouco satisfeito.

Por último, com o intuito de relacionar as diferentes variáveis e perceber o comportamento global dos diferentes indivíduos (face à procura deste espaço museológico, no domínio das práticas e das representações), procedemos a uma Análise Fatorial de Correspondências Múltiplas (AFCM). No que concerne à análise realizada, não foram utilizadas todas as variáveis e modalidades codificadas, utilizando-se apenas 15 variáveis num total de 75 modalidades sendo que as restantes excluídas não acrescentam diferenciação nos comportamentos dos indivíduos.

Desta classificação resultaram seis fatores (Quadro I), sendo que o primeiro fator (que assume um valor 
próprio de 0,06 ) apresenta o maior poder explicativo, designadamente $14,28 \%$, enquanto que nos restantes fatores o poder explicativo é menor, variando entre $12,85 \%$ do fator 2 e os $5,01 \%$ do fator 6 . Assim, foram considerados os primeiros 4 eixos/fatores que explicam cerca de $41 \%$ da variância acumulada, sendo que a partir do quinto eixo a informação começava a ser redundante e não diferenciadora.

Quadro I

Matriz de valores próprios

\begin{tabular}{|c|c|c|c|}
\hline Fatores & Valores próprios & $\begin{array}{c}\text { Percentagem } \\
\text { explicativa }\end{array}$ & $\begin{array}{c}\text { Percentagem } \\
\text { acumulada }\end{array}$ \\
\hline 1 & 0,063 & 14,28 & 14,28 \\
\hline 2 & 0,057 & 12,85 & 27,13 \\
\hline 3 & 0,034 & 7,61 & 34,74 \\
\hline 4 & 0,028 & 6,33 & 41,07 \\
\hline 5 & 0,027 & 6,03 & 47,10 \\
\hline 6 & 0,022 & 5,01 & 52,11 \\
\hline Total & 0,23 & 52,11 & \\
\hline
\end{tabular}

Fonte: AMADO (2011)

0 primeiro fator, que explica cerca de $14 \%$ da variância inicial e que denominamos como o grupo de "Visitantes Indiferentes", é caracterizado por inquiridos que representam uma fatia da população inativa, em grande parte dos casos reformados e com níveis de instrução bastante baixos.

Ao nível da procura turística caracterizam-se por um tipo de indivíduos que procuram uma exploração generalista e exploratória, na medida em que se deslocaram a este território para efetuarem uma visita global, estando o Museu do Pão incluído num vasto conjunto de ofertas.

Globalmente são indivíduos com bastante tempo disponível, que escolheram efetuar a visita ao Museu durante a semana, permanecendo neste espaço mais de duas horas, fazendo-se acompanhar de amigos e familiares, tendo obtido conhecimento deste espaço museológico através de juntas de freguesias, associações ou coletividades de apoio à terceira idade.

Ao nível das representações museológicas defendem que as atividades desenvolvidas pelo Museu do Pão the proporcionam uma enorme projeção a nível nacional e internacional, dando ainda, oportunidade a este tipo de grupo de recordar costumes, tradições e vivências ancestrais.

No que concerne à opinião que este conjunto de indivíduos lança sobre esta estrutura museológica, o reflexo dos indivíduos centra-se na adequação deste espaço a todas a faixas etárias.
0 segundo fator explica menos percentagem da variância inicial (cerca de 12\%) e, tendo em conta as modalidades que o integram direta e indiretamente, foi denominado como o grupo de "Visitantes Interessados". Com efeito, apesar de ser um fator mais específico, é caracterizado por indivíduos com idades entre os 50 e os 59 anos, com habilitações ao nível do Ensino Superior, em grande parte das situações desempregados, reformados ou docentes.

Os elementos que distinguem este fator do anteriormente referido prendem-se fundamentalmente com as práticas e representações da visita. Ao nível das práticas turísticas destaca-se o facto de estes indivíduos já terem efetuado, em tempos passados, uma visita ao Museu do Pão, nomeadamente num período de tempo entre 6 meses a 1 ano, continuando este espaço a constituir a principal razão da sua presença no Município. Portanto, trata-se de um conjunto de visitantes de frequência assídua que vêm conhecer esta estrutura museológica em particular. 0 conhecimento prévio do Museu surge através da escola/faculdade, sendo a deslocação motivada fundamentalmente para ocupar o tempo, surgindo de forma individual ou com amigos neste espaço museológico.

As preocupações pelas atividades didáticas que o Museu oferece, aliado ao seu forte papel educativo constituem no domínio das representações, elementos privilegiados por este grupo de inquiridos.

Em suma, trata-se de um conjunto de indivíduos que direciona a ocupação do seu tempo livre para as práticas culturais e museológicas, dando primazia à temática desenvolvida por este espaço museológico, onde a função pedagógica assume um papel de destaque.

Com uma menor taxa de explicação (cerca de 7\%) surge o eixo 3 que reflete uma realidade ainda mais específica que a anterior e que pode ser denominado por "Visitantes Lúdicos". O presente fator reflete comportamentos de indivíduos muito jovens e, como tal, com níveis de escolaridade intermédios e em processo de prolongamento, com ocupação predominantemente estudantil.

Trata-se de um grupo com estada recorrente no Museu do Pão, mas que não permanecem por um longo período de tempo, uma vez que esta população conhece os sítios/pontos de interesse do concelho, motivados para um tipo de exploração ligada ao turismo de neve e de paisagem. No geral, estamos perante um tipo de visitante que se desloca ao Município para se divertir dentro de um quadro de lazer que não engloba somente cultura.

No domínio das representações deste espaço museológico constituem um tipo de visitante que re- 
conhece o enorme poder atrativo do Museu, bem como a sua elevada expressividade a nível nacional e internacional.

O eixo 4, que explica apenas 6,33\% da variância e especifica ainda mais a análise, foi denominado por "Visitantes Culturais" No fundo, integra comportamentos que se caracterizam com indivíduos em idade ativa, com habilitações no Ensino Básico e Ensino Superior, que se encontram desempregados ou a estudar.

No que diz respeito às práticas turísticas trata-se de um conjunto de indivíduos com estadia recorrente no Município, sendo as principais razões apontadas para a sua movimentação a gastronomia e o património cultural, dando destaque às estruturas municipais. No geral, visitaram os pontos fulcrais da rota patrimonial da cidade, nomeadamente o Museu do Brinquedo, o Museu da Eletricidade, o Centro de Interpretação da Serra da Estrela, entre outros.

Ao nível das representações museológicas tratase de um grupo de indivíduos com forte apetência para valorizar favoravelmente o local, a sua autenticidade e características peculiares, surgindo os produtos locais como aspetos de valorização superior.

\section{Conclusão}

Os Museus, na amplitude de funções como a recolha, a salvaguarda, a valorização e a investigação de elementos de relevância cultural e natural, podem desempenhar um papel preponderante se integrados em estratégias que visem o desenvolvimento local (entendido como um processo participativo de valorização de recursos, nas dimensões território, património e população).

A localização privilegiada do Museu do Pão, num dos principais eixos de acesso ao topo da Serra da Estrela, o interesse inerente à temática, uma vez que o pão constitui um dos principais alimentos da dieta mediterrânea, aliado à multiplicidade de ações culturais que promove, às diversas atividades didático pedagógicas que fomenta, pela sua relevante contribuição no estudo da história local, ou até mesmo regional, pelos usos, modos de vida e tradições que recupera, pelas inúmeras temáticas que desenvolve em torno do pão, são alguns dos fatores que se conjugam para o enorme sucesso desta iniciativa.

O visitante do Museu do Pão, de um modo geral está ciente da importância na preservação desta atividade, permitindo por um lado, aos mais velhos recordar tradições e vivências ancestrais, e por outro aos mais jovens ensinar e dar a conhecer todas as técnicas e utensílios atualmente em declínio, usados na produção do pão. A maioria dos inquiridos reconhece que esta unidade museológica desenvolve um forte papel educativo e contribui para o desenvolvimento local, uma vez que a identidade e especificidade de cada lugar são aspetos fundamentais na revitalização de uma comunidade. Nestas circunstâncias pode afirmar-se como uma das mais importantes estruturas dinamizadoras da área geográfica onde se insere.

Importa referir também que a Serra da Estrela têm vindo a beneficiar, em particular nestas últimas décadas, de uma revalorização do respetivo potencial eco cultural, tornando-se atrativa ao nível paisagístico, ambiental, e histórico-cultural.

De facto, emergem hoje "novas" vocações que, ligadas ao património natural, histórico e cultural, tendem a dinamizar estes espaços e a dotá-los de novas atratividades. Estas vocações estão ligadas, de forma crescente, às atividades turísticas nas suas múltiplas formas, que vão desde a contemplação dos elementos paisagísticos aos desportos radicais, passando pela revalorização e manutenção de atividades tradicionais.

A oferta diversificada de produtos turísticos de qualidade surge como um dos elementos chave do desenvolvimento deste local. Do ponto de vista económico, os benefícios esperados são o aumento dos empregos para os residentes locais, o acréscimo de receitas das atividades relacionadas com o turismo, o estímulo ao aparecimento de novas empresas turísticas, promovendo e diversificando a economia local, encorajando à produção de bens e produtos locais, a melhoria da oferta de serviços e equipamentos. Os benefícios passam também pela promoção do bem-estar, pelo apoio à educação ambiental para visitantes e locais e pelo estimular do desenvolvimento e valorização da cultura.

Contudo, a crescente procura turística, com a consequente afluência de turistas terá de implicar novas formas de estruturação do território, aspetos, até ao momento, pouco considerados tanto nas planificações turísticas como ambientais. Compete aos agentes responsáveis pela gestão, ocupação e promoção deste espaço, a sua utilização racional e sustentável, dado que o desenvolvimento local em meio rural se pretende cada vez mais integrado e sustentado (AMADO, 2011).

\section{Bibliografia}

Amado, M. (2011) - O Museu do Pão em Seia: uma iniciativa de desenvolvimento local de expressão nacional. 
Dissertação de Mestrado em Geografia Humana (Ordenamento e Desenvolvimento), Universidade de Coimbra, Coimbra.

Abreu, D. (2006) - "Análise de Dados II. Programa". Estudos para o Planeamento Regional e Urbano $\mathrm{n}^{\circ} 69$, Centro de Estudos Geográficos, Lisboa.

BRITo, J. (2004) - "Pessoas e Lugares". Jornal de Animação da Rede Portuguesa LEADER +. II Série, $\mathrm{n}^{\circ} 24$, Novembro de 2004.

Carvalho, P. (2003) - "Património Cultural e Iniciativas de Desenvolvimento Local no Espaço Rural". In: Caetano, L. (coord.) - Território do Global ao Local e Trajectórias de Desenvolvimento, Centro de Estudos Geográficos, Coimbra, pp. 200-227.

Carvalho, P. (2009) - Património Construído e Trajectórias de Desenvolvimento em Áreas de Montanha: o exemplo da Serra da Lousã. Câmara Municipal da Lousã, Lousã.

Fernández, L. (1999) - Introducción a la Nueva Museologia. Alianza Editorial, Madrid.

R, A. (2005) - "Contributos para o Debate Teórico sobre o Desenvolvimento Local: um ensaio baseado em experiências investigativas". Revista Lusófona de Educação, n 5, pp. 63-83.

R, L. et al (1995) - Statistique Exploratoire Multidimensionelle. Dunod, Paris,
Mendes, J. (1999) - "O Museu na Comunidade: Património, Identidade e Desenvolvimento". Gestão $e$ Desenvolvimento, $\mathrm{n}^{\circ} \quad 8$, Universidade Católica Portuguesa, Viseu, pp. 217-231.

MoreIRA, F. (2000) - "The Creation Process of a local Museum". In: Bruno, C. et al. (ed.) - Sociomuseology, Edições Universitárias, Lisboa.

Moreno, L. (2002) - Desenvolvimento Local em Meio Rural: Caminhos e Caminhantes. Dissertação de Doutoramento, Faculdade de Letras da Universidade de Lisboa, Lisboa.

Neves, J e Santos, J. (2006) - Os Museus em Portugal no período de 2000-2005: Dinâmicas e Tendências. Observatório das Actividades Culturais, Lisboa.

Riviére G. (1989) - La Muséologie, Cours de Muséologie/ textes et témoignages. Bordas, Paris.

Primo, J. (2000) - Museus Locais e Ecomuseologia: estudo do Projecto para o Ecomuseu da Murtosa. Dissertação apresentada na ULHT para a obtenção do grau de Mestre em Museologia, Lisboa.

Primo, J. (2006) - "A importância dos Museus locais em Portugal". Cadernos de Sociomuseologia, $\mathrm{n}^{\circ} 25$, ULHT, Lisboa, pp.41-62.

Valuina, J. (2002) - Manual para Agentes do Desarrolo Rural. Mundial Prensa, Madrid.

VARINE, H. (1996) - "Respostas de Hugues de Varine a Mário Chagas". Cadernos de Sociomuseologia, $n^{\circ}$ 5, ULHT, Lisboa. 